\title{
ADDENDUM TO \\ DAILY CHANGES IN VENTILATORY CAPACITY IN SMOKERS AND NON-SMOKERS*
}

\author{
BY \\ G. C. R. CAREY, M.D., D.P.H., D.I.H., A.M.I.C.E., \\ T. A. J. DAWSON, M.D., M.R.C.P.Ed., D.P.H., AND J. D. MERRETT, B.Sc., Ph.D. \\ From the Department of Social and Preventive Medicine, the Queen's University of Belfast
}

It has been suggested that the data already reported should have been analysed by a different method from that which we adopted. The suggested method, which is similar to a certain type of splitplot analysis (e.g. Cochran and Cox, 1957), differs from the method we used in that more than one source of variation is allowed for; e.g. variation between different subjects, variation in the change during the day for a given man. We agree that the split-plot analysis of variance might have been preferable because it provides a more valid comparison of:

(a) The average FEV(1) or FVC between smokers and non-smokers, and of

(b) The average decline during the day of FEV(1) or FVC between smokers and non-smokers.

We considered this approach before publishing our results but decided against it because of heterogeneity of error between smokers and non-smokers. However, we now realize that no significant heterogeneity exists.

We have re-analysed our data using the split-plot technique which shows that the comparisons between smokers and non-smokers could have been made for all days combined instead of for each day separately as in our Table IV. Thus our data may be summarized by the following Table:

\begin{tabular}{l|c|c|c|c}
\hline \multirow{2}{*}{\multicolumn{1}{c|}{ Mean Values }} & \multicolumn{2}{c|}{ FEV(1) } & \multicolumn{2}{c}{ FVC } \\
\cline { 2 - 4 } \cline { 3 - 4 } Smokers & a.m. & p.m. & a.m. & p.m. \\
\hline Non-smokers & 3.894 & 3.823 & 5.074 & 5.043 \\
\hline Effects & $4 \cdot 186$ & 4.143 & $5 \cdot 183$ & 5.186 \\
Non-smokers - smokers & $0.305 \pm 0.422$ & $0.126 \pm 0.446$ \\
a.m. - p.m. & $0.057^{*} \pm 0.017$ & $0.014 \pm 0.018$ \\
(a.m. - p.m.) smokers - & & & \\
(a.m. - p.m.) non-smokers & $0.028 \pm 0.035$ & $0.034 \pm 0.036$ \\
\hline
\end{tabular}

* Significant at $\mathbf{P}<0.05$.

The analysis shows that average FEV(1) and FVC were not significantly greater in non-smokers than in smokers as we originally concluded. The new analysis also shows that the declines in FEV(1) and FVC during the day were not significantly greater in smokers than in non-smokers.

We are indebted to Mr G. Berry of the Medical Research Council's Pneumoconiosis Research Unit for drawing our attention to these points.

\section{REFERENCE}

Cochran, W. G., and Cox, G. M. (1957). "Experimental Designs", 2nd ed., chap. 7, pp. 293-316 (Factorial experiments with main effects confounded: split-plot designs). Chapman and Hall, London. 